\title{
The effects of extrusion conditions on the properties of Amplang, a traditional fish snack in Borneo
}

\author{
*Nor Qhairul Izzreen M.N., Siti Amriah, C.G. and Noorakmar, A.W. \\ Faculty of Food Science and Nutrition, University Malaysia Sabah, Jalan UMS, 88400 Kota Kinabalu, \\ Sabah, Malaysia
}

\begin{abstract}
Article history:
Received: 4 February 2020

Received in revised form: 2

April 2020

Accepted: 8 April 2020

Available Online: 4 May

2020
\end{abstract}

Keywords:

Extrusion technique,

RSM,

Fish snack,

Physical and functional

characteristics

DOI:

https://doi.org/10.26656/fr.2017.4(5).052

\section{Introduction}

Snack foods have become an integral part of the diet worldwide, with fish crackers being the most popular snack food in many Southeast Asian countries (Taewee, 2011). Fish crackers are prepared by blending the flesh of the fish with starch and water, followed by shaping the mixture into round, oblique, stick or longitudinal forms that are subsequently boiled or steamed for gelatinisation (Chng and Kuang, 1991). The product is then cooled, sliced into different shapes, and dried. In Malaysia, a small, round-shaped fish snack known as Amplang is a popular snack among the local people, particularly in certain parts of Borneo (Sabah). Hence, there is potential for this fish snack cottage industry to be transformed into a bigger industry in Sabah due to its popularity. According to the State Development Department of Sabah (2016), the production of fish snacks is approximately 600-700 kilograms per month and the production is expected to increase based on the market demand.

Extrusion cooking is one of the major processes involved in producing expanded snack foods. It is a continuous process of cooking and shaping (forming), in which various conditions such as extruder type, screw configuration, feed moisture, the temperature profile in the barrel, screw speed, feed rate, and die geometry are essential to produce the unique physical and chemical properties of the product. In the extruder, raw materials are thermo-mechanically cooked at high temperature, pressure, and shear stress conditions generated in the screw-barrel assembly (Moscicki, 2011). The cooked dough is subsequently texturised and shaped in the die. The use of extruder machines to replace the traditional methods in food processing is energy-efficient and cheaper, thereby resulting in the reduction of raw materials (19\%), labour (14\%), and capital investment (44\%) (Deshpande and Poshadri, 2011). High-quality products can be produced as extrusion is a hightemperature process that helps to reduce nutrient loss and improve the digestion of protein and starch.

Furthermore, single- and twin-screw extruders have been used to develop dry expanded snack food products from fish mince and starchy ingredients. For instance, Noorakmar et al. (2012) and Tumuluru and Sokhansanj (2013) successfully developed snack foods using the extrusion of fish and different types of starch flour. In another study, Singh et al. (2014) optimised the 
extruder conditions for fish-rice-corn blends in food snacks with satisfactory customer acceptance. The production of Amplang as a popular traditional food snack in Sabah has always been performed conventionally and the scale of production is only sufficient for the local market. Hence, to increase the production of Amplang and satisfy the market demand outside of Sabah as well as for export to other countries, other methods that are non-labour intensive should be utilised for the efficient production of this snack food. At present, the conventional method that is performed manually by experienced workers limits the production of Amplang. It is envisaged that the use of the extrusion method can increase the production of Amplang and at the same time, retain the same formulation and properties of the snack, thus boosting the economy of entrepreneurs in Borneo, especially in Tawau, Sabah.

Response surface methodology (RSM) is a technique that could determine the relationship between the response and the chosen independent variables. It is used to improve a process or product by mapping a response surface over a specific region of interest, optimising the response, or for selecting operating conditions to achieve target specifications or customer requirements (Singh et al., 2014). Hence, this study aims to determine the effects of barrel temperature and screw speed on the production of Amplang based on their physical and functional characteristics (hardness, bulk density, expansion ratio, and water absorption and solubility indexes) using RSM.

\section{Materials and methods}

\subsection{Sample preparation}

White fish fillets were manually cut into small pieces, washed with tap water, and dried using a drying cabinet (M-412294, Sanyo Electric, Japan) at $65^{\circ} \mathrm{C}$ for 5 hrs to achieve a final moisture content of $12 \%$. The fish fillets were blended for $30 \mathrm{~s}$, molded, and cut into $1 \mathrm{~cm}^{2}$ per piece. The cut fillets were dried again using a drying cabinet (M-412294, Sanyo Electric, Japan) at $65^{\circ} \mathrm{C}$ for 5 hrs. Approximately $500 \mathrm{~g}$ of dried fish fillets were blended using a blender (Waring Laboratory Blender, Model 70110H, United States) for 2 mins with a moderate speed to form fish powder with particle sizes of not more than $25 \mu \mathrm{m}$. The fish powder was mixed with other ingredients as shown in Table 1 until a dough was formed. The moisture content of the mixed dough was maintained at $13 \%$ or below. The dough was kept in a plastic container coated with aluminum and stored overnight in the refrigerator at $4^{\circ} \mathrm{C}$.

\subsection{Amplang formulations}

The formulation of the Amplang fish snack using the extrusion process was based on a method used by a local commercial producer, Muhibbah Raya, Tawau, Sabah with some modifications. Table 1 shows the formulation of Amplang.

Table 1. Fish snack formulations (Amplang) for extruder application

\begin{tabular}{ccr}
\hline Materials & Quantity (\%) \\
\hline Fish powder & 17 & \\
Cassava flour & 43.84 & \\
Cornflour & 29.23 & \\
Salt & 2.39 & \\
Sugar & 6.1 & \\
Baking powder & 0.85 & \\
Soda powder & 0.36 & \\
MSG & 0.23 & \\
\hline Muhibbah Raya, Tawau, Sabah with some
\end{tabular}

Source: M
modifications

\subsection{Fish snack production using extrusion techniques}

A total of $4 \mathrm{~kg}$ of dough mix was required for thirteen experimental runs, with approximately $300 \mathrm{~g}$ of dough mix used for each run. The dough was inserted into the extruder's feeder after setting the parameters for the extrusion process. The extrudate was pushed out through a $10 \mathrm{~mm}$ diameter screw and cut using cutters at the ends of the die. The extruded products were left to cool at room temperature for $5 \mathrm{~h}$ and stored in an airtight container prior to analysis.

\subsection{Extruder conditions}

A Brabender ${ }^{\circledR}$ single-screw extruder $(20 \mathrm{DN})$ with a diameter of $1.90 \mathrm{~cm}$ (Model 823500, OHG Duisburg, Germany) equipped with a feeding device (AEV 330) was used to produce the Amplang fish crackers. The length to diameter ratio of the barrel was $20: 1$ and the extruder was powered by a $2.2 \mathrm{kWh}$ motor with screw speeds ranging from $0-250 \mathrm{rpm}$. The compression ratio and die nozzle diameter used were $3: 1$ and $10.0 \mathrm{~mm}$, respectively, and the screw speeds were set at $146 \mathrm{rpm}$, $177 \mathrm{rpm}$, and $208 \mathrm{rpm}$, respectively. The dough mixture was fed into the gravity feeder funnel and the barrel was equipped with a cold compressed electric air heater controlled by a thermostat to adjust the temperature. The temperatures of the extruder barrel were set as follows: a) first zone $\left.\left(80^{\circ} \mathrm{C}\right), \mathrm{b}\right)$ second zone $\left(100^{\circ} \mathrm{C}\right)$, and c) third zone $\left(100^{\circ} \mathrm{C}, 120^{\circ} \mathrm{C}\right.$, and $\left.140^{\circ} \mathrm{C}\right)$ for each experimental run. The extruder was conditioned prior to sample processing and the extrudate was cut into small round shapes by the cutter located at the end of the screw. 


\subsection{Determination of moisture content}

The moisture content was determined using the oven -drying method described previously (AOAC, 2000). Approximately $2 \mathrm{~g}$ of samples were placed in the oven at $103^{\circ} \mathrm{C}$ for $24 \mathrm{hrs}$. The samples were cooled in a desiccator and weighed prior to analysis.

\subsection{Determination of response}

In this study, the physical (hardness and bulk density) and functional (expansion ratio, water absorption analysis, and water solubility analysis) characteristics of the Amplang fish crackers were identified as the observed responses. Table 2 shows the central composite design (CCD) of the extraction parameters for all the responses investigated in this study.

The fitted model was assessed based on the $\mathrm{R}^{2}$ value and the variation in the dependent variables was evaluated according to the response surface graphs and factor parameters. The response surface equation of the second-order polynomial model used in the surface response methodology is as follows:

$$
\eta=\beta o+\sum_{i=1}^{k} \beta i x i+\sum_{i=1}^{k} \beta i i x i+\sum_{i=1}^{k-1} \sum_{j=i+1}^{k} \beta i j x i x j
$$

\subsection{Physical properties}

\subsubsection{Hardness}

The texture of Amplang was measured using a texture analyser (TA.XT Plus Analyzer, Texture Technologies, Scarsdale, New York). Approximately 15 mm-sized (in length) Amplang fish crackers were used for the measurement of texture. A cylinder probe (10 $\mathrm{mm}$ ) was used to press the samples based on the following settings: (1) $1 \mathrm{mms}^{-1}$ pretest speed, (2) 0.5 $\mathrm{mms}^{-1}$ speed during testing, (3) $1 \mathrm{mms}^{-1}$ speed after testing, (4) $10 \mathrm{~mm}$ distance, (5) $5 \mathrm{~g}$ triggering power, and (6) $70 \%$ sample suspension (Maskus and Arntfield, 2015). Three replicate runs were performed for each formulation.

\subsubsection{Bulk density}

The bulk density of Amplang was assessed by calculating the actual dimensions of the extrudate (Thymi et al., 2005). The diameter and length of the samples were measured using a Vernier caliper. Five samples were randomly selected, and the bulk density was calculated using the following equation:

$$
\text { Bulk density }\left(\mathrm{g} / \mathrm{cm}^{3}\right)=M /\left(1 / 4 \mathrm{x} \mathrm{d}^{2} \mathrm{x} \mathrm{L}\right)
$$

Where $\mathrm{m}=$ extruded product weight, $\mathrm{d}=$ diameter of extrusion product, and $\mathrm{L}=$ length of extrusion product

\subsection{Functional properties}

\subsubsection{Expansion ratio}

The expansion ratio of the samples was measured using the equation formula developed by Rayas-Duarteet al. (1998) as shown below:

Expansion ratio $=$ Extruded diameter $/$ mold diameter

\subsubsection{Water absorption index}

Water absorption was measured according to the method developed by Anderson et al. (1970) with some modifications. Approximately $4.5 \mathrm{~g}$ of extruded sample was blended and mixed with $30 \mathrm{~mL}$ of water in a centrifuge tube at room temperature for 30 mins. The sample was stirred slowly using a glass rod for $1 \mathrm{~min}$. The sample was centrifuged for 10 mins at $3000 \mathrm{rpm}$ and evaporated to dryness at $110^{\circ} \mathrm{C}$ overnight. The water absorption index was calculated based on the following equation:

Water absorption index $=$ wet sediment weight/dry sample weight

\subsubsection{Water solubility index}

The water solubility index was measured using the same method described for the water absorption index. The water solubility index was calculated based on the following equation:

Water solubility index $=$ dry supernatant weight/dry sample weight $\mathrm{x} 100$

\subsection{Statistical analysis}

The Design Expert version 7.0 software was used for the regression analysis of the experimental data and the generation of surface and contour response plots based on the parameters established for this study. Additionally, the analysis of variance (ANOVA) was

Table 2. Design of composite center for extruder parameter response

\begin{tabular}{lccccccc}
\hline Type of Response & Unit & Experiment & Minimum value & Maximum value & Average & Standard deviation & Ratio \\
\hline Bulk density & $\mathrm{g} / \mathrm{cm}^{3}$ & 13 & 0.09 & 0.21 & 0.13 & 0.04 & 2.33 \\
Hardness & $\mathrm{N}$ & 13 & 4557 & 29750 & 15404 & 7258 & 6.53 \\
Expansion Ratio & - & 13 & 0.5 & 1.7 & 1.1 & 0.41 & 3.4 \\
Water Absorption Index & $\mathrm{g} / \mathrm{g}$ & 13 & 2.58 & 4.01 & 3.24 & 0.34 & 1.55 \\
Water Solubility Index & $\%$ & 13 & 19.8 & 29.8 & 24.09 & 2.52 & 1.55 \\
\hline
\end{tabular}

Source: Design Expert Software version 7.0 
used to identify the significant differences between the tested parameters.

\section{Results and discussion}

\subsection{Experimental results}

The central composite design and responses for the dependent variables (hardness, bulk density, expansion ratio, water absorption, and water solubility) are shown in Tables 2 and 3. The regression analysis was employed to check the fit of the full response surface model for every response investigated in this study including all linear $(\mathrm{A}, \mathrm{B})$, interaction $(\mathrm{AB})$, and quadratic $\left(\mathrm{A}^{2}, \mathrm{~B}^{2}\right)$ terms.

The examination of the fitted model was necessary to ensure that an adequate representation of the true system was developed in this study. To develop the fitted model, all insignificant terms were eliminated, and the fitted model is shown in Table 4. A small $\mathrm{R}^{2}$ value indicates a low relevance of the dependent variables analysed in the model. The model is shown to fit well with the actual data when the $\mathrm{R}^{2}$ value approaches unity (Myers and Montgomery 2002).

The analysis of variance (ANOVA) was used to evaluate the significance of the quadratic polynomial model equation. In this analysis, the terms in the model that have a large $\mathrm{F}$-value and a small $\mathrm{P}$-value indicate a more significant effect on the response of the variable investigated.

The estimated response function and the effects of the independent variables (A: barrel temperature and B: screw speed) on the dependent variables (hardness, bulk density, expansion ratio, water absorption, and water solubility) are shown in Figure 1.

\subsection{Hardness}

The hardness of the Amplang products investigated in this study ranged from $45.57 \mathrm{~N}$ to $246.33 \mathrm{~N}$. It was revealed that the coefficients and their corresponding interaction effects of both the barrel temperature and screw speed were shown to be significant $(P \leq 0.01)$. A moderate coefficient of determination $\left(\mathrm{R}^{2}\right)$ value of 0.7149 was obtained for hardness, thereby indicating that only $71.48 \%$ of the fitted model can be explained in this study. Based on Figure 1 (a), increases in the barrel temperature and screw speed were shown to increase the hardness of the Amplang fish extrudate. High temperatures can cause the fibre structures on the outside of the product to become hard and a high moisture content of feed materials can result in the products becoming less porous.

In most cases, high barrel temperatures and die temperatures may increase the crispiness of the extrudate due to the low moisture content and increased porosity of the structure (Verma, 2010). However, the moisture content of $13 \%$ obtained in this study may not have been low enough to reduce the hardness of the extrudate. Generally, fish extrudates produced with a low expansion rate have a hard texture. Low expansion rates contribute to high bulk density and subsequently, increases the hardness of the product (Wani et al., 2015).

\subsection{Bulk density}

The bulk density of the Amplang products formed in this study ranged from 0.09 to $0.21 \mathrm{~g} / \mathrm{cm}^{3}$. The barrel temperature and screw speed coefficients were significant $(P \leq 0.01)$ and their corresponding interaction effects on bulk density were also shown to be significant. A high coefficient of determination $\left(R^{2}\right)$ value of 0.9595 for bulk density was obtained in this study, thereby indicating that the model was suitable to represent the true relationships among the selected parameters. Bulk density is an index that measures the extent of puffing as well as the expansion in all directions. As shown in Table 2 and Figure 1 (b), the bulk density of the fish extrudate decreased as the barrel temperature and expansion ratio increased. However, the bulk density increased when the barrel temperature exceeded a temperature of $140^{\circ} \mathrm{C}$. The minimum bulk density was achieved at a barrel temperature of $120^{\circ} \mathrm{C}$ and an expansion ratio of $177 \mathrm{rpm}$. This observation was consistent with the findings by Singh et al. (2014) who reported that bulk density reduced with the decrease in expansion ratio and the increase in barrel temperature.

Some of the factors that can influence bulk density are barrel temperature, gelatinisation process, and moisture content of the dough. Gelatinisation and moisture content were shown to be positively correlated with bulk density, whereas screw speed had an inverse association with bulk density (Rayas-Duarte et al., 1998; Shankar and Bandyopadhyay, 2005; Singh et al., 2014). High barrel temperatures and low moisture content were also shown to increase the porosity of the dough when the products exit the extruder, thus resulting in the reduction of bulk density (Tumuluru and Sokhansanj, 2013). However, the increase in bulk density at higher barrel temperatures is due to starch degradation at high temperatures.

\subsection{Expansion ratio}

The expansion ratio of the Amplang products ranged from 1.00 to 2.67 for all the barrel temperatures and screw speeds investigated in this study. The coefficient values for the barrel temperatures and screw speeds as well as their corresponding interaction effects were not 
a)

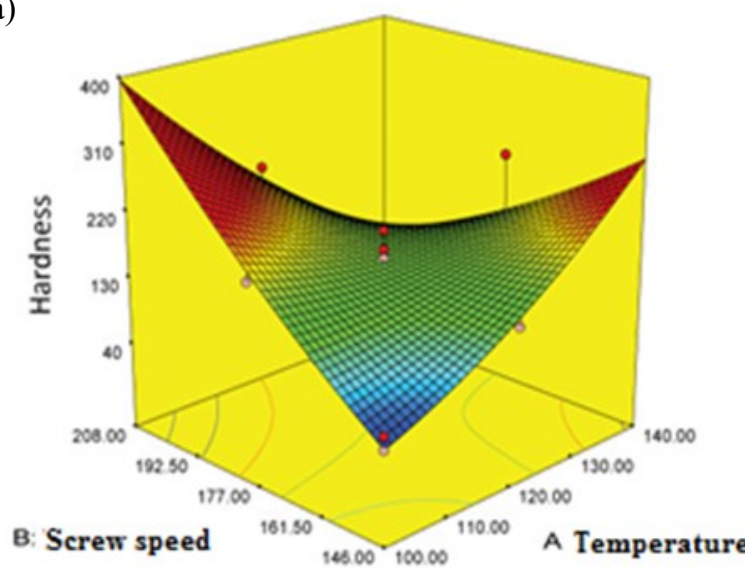

c)

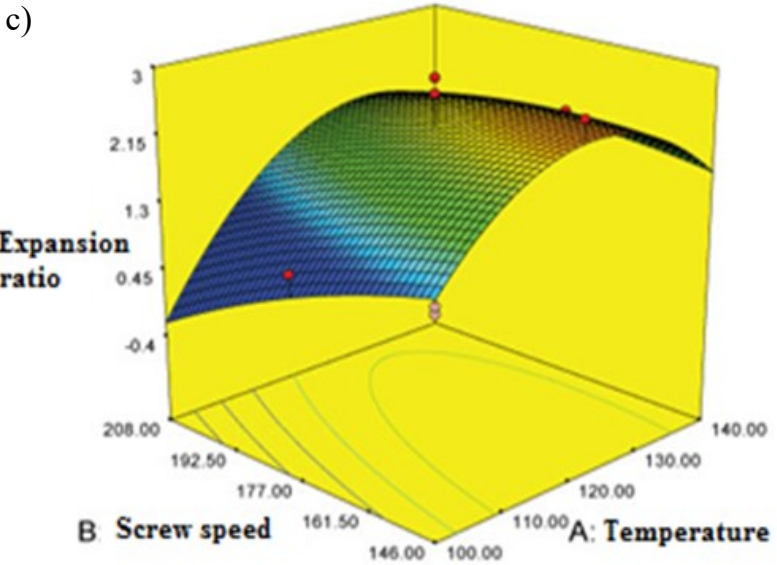

b)

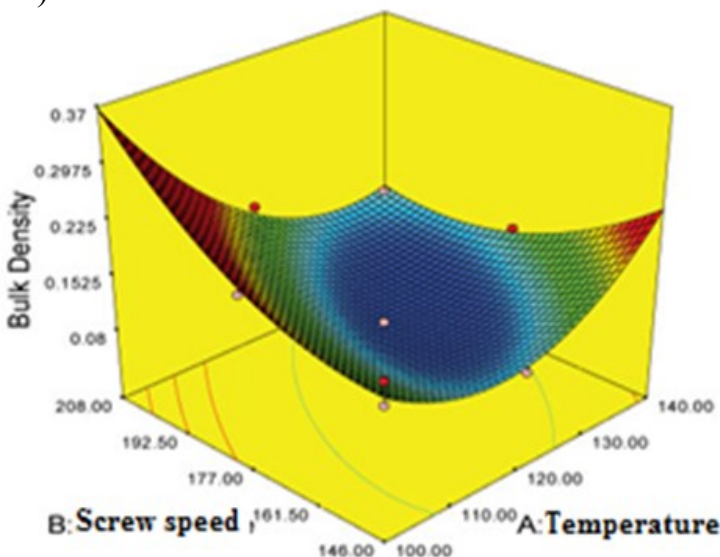

d)

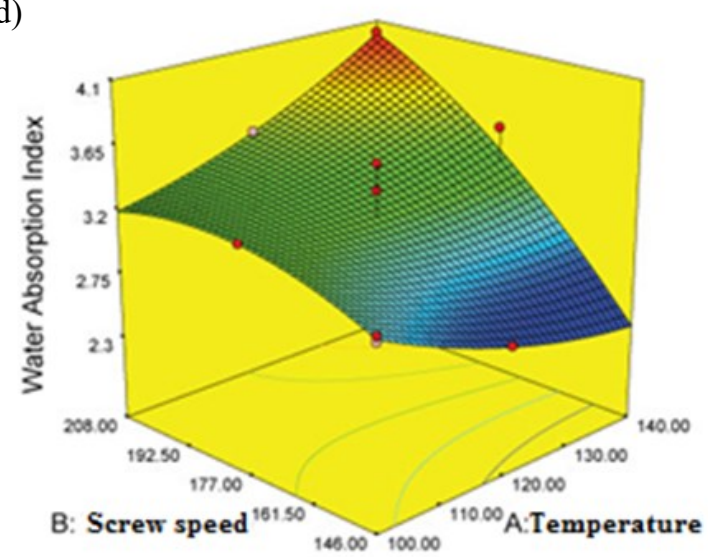

e)

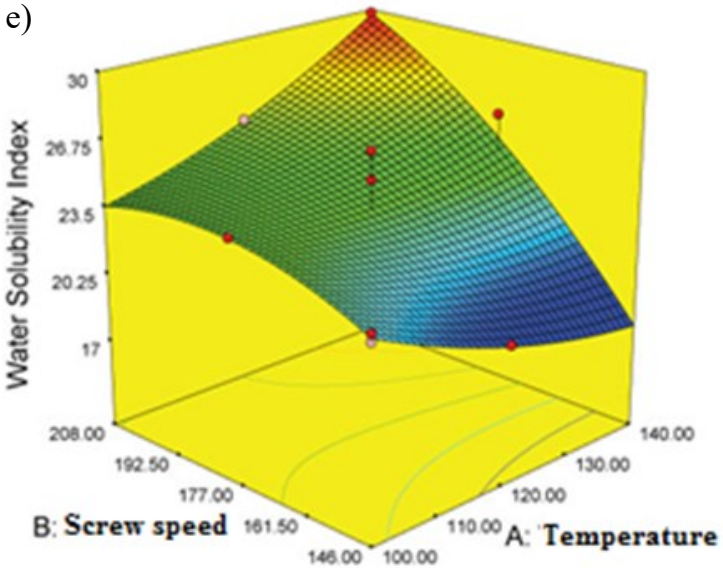

Figure 1. Response surface plots showing the effects of expansion ratio and barrel temperature on 2 (a) hardness, (b) bulk density, (c) expansion ratio, (d) water absorption and (e) water solubility

Table 3. Central composite design for optimizing the extrusion condition for all responses according to the 2 nd order response surface models

\begin{tabular}{|c|c|c|c|c|c|c|c|}
\hline \multirow[b]{2}{*}{ Combination } & \multicolumn{2}{|c|}{ Factor } & \multicolumn{5}{|c|}{ Response } \\
\hline & Temp $\left({ }^{\circ} \mathrm{C}\right)$ & $\begin{array}{c}\text { Screw speed } \\
(\mathrm{rpm})\end{array}$ & Bulk Density & Hardness & $\begin{array}{c}\text { Expansion } \\
\text { Ratio } \\
\end{array}$ & $\begin{array}{l}\text { Water Absorption } \\
\text { Index }\end{array}$ & $\begin{array}{l}\text { Water Solubility } \\
\text { Index } \\
\end{array}$ \\
\hline 1 & 120 & 177 & 0.09 & 195.76 & 2.16 & 3.34 & 24.87 \\
\hline 2 & 140 & 177 & 0.14 & 246.33 & 2 & 3.53 & 26.24 \\
\hline 3 & 100 & 146 & 0.16 & 45.57 & 1.16 & 2.96 & 21.93 \\
\hline 4 & 140 & 177 & 0.14 & 105.35 & 1.5 & 3.21 & 23.89 \\
\hline 5 & 100 & 177 & 0.21 & 189.02 & 1 & 3.27 & 24.24 \\
\hline 6 & 120 & 177 & 0.09 & 169.5 & 2 & 2.99 & 22.22 \\
\hline 7 & 120 & 177 & 0.09 & 157.13 & 2.16 & 3.13 & 23.18 \\
\hline 8 & 120 & 146 & 0.11 & 129.92 & 2 & 2.58 & 19.25 \\
\hline 9 & 120 & 177 & 0.09 & 137.63 & 2.67 & 3.53 & 26.27 \\
\hline 10 & 120 & 177 & 0.09 & 140.17 & 2.67 & 3.1 & 23.04 \\
\hline 11 & 120 & 208 & 0.17 & 227.76 & 1.5 & 3.5 & 25.94 \\
\hline 12 & 140 & 208 & 0.12 & 67.64 & 2 & 4.01 & 29.8 \\
\hline 13 & 100 & 146 & 0.19 & 62.74 & 1.25 & 3 & 22.32 \\
\hline
\end{tabular}


Table 4. Response surface model for all responses of fish extrudates

\begin{tabular}{cccc}
\hline Response & Quadratic polynomial model & $\mathrm{R}^{2}$ & $\mathrm{P}$-value \\
\hline Hardness & $160.04-17.27 \mathrm{~A}+34.68 \mathrm{~B}-140.33 \mathrm{AB}+25.95 \mathrm{~A}^{2}-18.80 \mathrm{~B}^{2}$ & 0.7149 & $P \leq 0.01$ \\
Bulk density & $0.090-0.042 \mathrm{~A}+0.021 \mathrm{~B}-0.077 \mathrm{AB}+0.087 \mathrm{~A}^{2}+0.050 \mathrm{~B}^{2}$ & 0.9595 & $P \leq 0.01$ \\
Expansion ratio & $2.33+0.47 \mathrm{~A}-0.18 \mathrm{~B}+0.75 \mathrm{AB}-0.99 \mathrm{~A}^{2}+0.52 \mathrm{~B}^{2}$ & 0.7902 & $P>0.05$ \\
Water absorption index & $3.22+0.051 \mathrm{~A}+0.46 \mathrm{~B}+0.35 \mathrm{AB}+0.10 \mathrm{~A}^{2}-0.18 \mathrm{~B}^{2}$ & 0.8421 & $P \leq 0.05$ \\
Water solubility index & $23.85+0.44 \mathrm{~A}+3.38 \mathrm{~B}+2.63 \mathrm{AB}+0.73 \mathrm{~A}^{2}-1.32 \mathrm{~B}^{2}$ & 0.8371 & $P \leq 0.05$ \\
\hline
\end{tabular}

found to be significant $(P>0.05)$. A moderate coefficient of determination $\left(\mathrm{R}^{2}\right)$ value of 0.7902 for bulk density was obtained in this study, thereby indicating that only $79.02 \%$ of the model can be explained by the regression model for the selected parameters (Table 4). Based on Figure 1 (c), the highest expansion ratio was achieved at a barrel temperature of $140^{\circ} \mathrm{C}$ and a screw speed of $208 \mathrm{rpm}$. Additionally, the expansion ratio was shown to increase when the barrel temperature increased [Figure 1 (c)]. However, the expansion ratio decreased when it reached a certain temperature. The optimal expansion ratio obtained in this study was at barrel temperatures ranging between 120 and $130^{\circ} \mathrm{C}$ and at screw speeds which did not exceed 177 rpm. The increase in the screw speeds reduced the viscosity of the starch due to the increase in shear rate, thus reducing the rate of expansion ratio. Moreover, high screw speeds resulted in shorter dwell time and reduced the degree of starch gelatinisation due to incomplete cooking (Hashimoto and Grossmann, 2003).

The expansion ratio observed in this study was shown to decrease when the barrel temperature exceeded $130^{\circ} \mathrm{C}$. A similar range of expansion rates for barrel temperatures between $150-170^{\circ} \mathrm{C}$ was also reported by Ilo et al. (2014) and Raleng et al. (2016) using maize grit and pineapple pomace powder, respectively, thereby indicating that the expansion ratio was closely associated with the type of raw materials used. The decrease in expansion ratio was due to excessive structural damage and starch degradation at high temperatures that caused the structures to become fragile. The reduction of expansion ratios at high temperatures was also a result of increased axial and longitude expansion. A similar finding by Dileep et al. (2010) using fish and rice flour blends showed that a higher moisture content influenced the starch gelatinisation process and affected the extrudate properties such as the expansion ratio.

\subsection{Water absorption index}

The water absorption index of the Amplang products ranged from 2.58 to 4.01 (Table 3 ). The barrel temperature coefficient was observed to be significant $(P$ $\leq 0.05)$, while the screw speed coefficient was not significant $(P>0.05)$. The corresponding interaction effect of barrel temperature and screw speed on the water absorption index was not shown to be significant as well. A high coefficient of determination $\left(\mathrm{R}^{2}\right)$ value of 0.8421 for bulk density was achieved in this study, thereby indicating that the model was suitable to represent the true relationships among the selected parameters (Table 4). Based on Figure 1 (d), the highest water absorption index at 4.01 was obtained at a barrel temperature of $140^{\circ} \mathrm{C}$ and a screw speed of $208 \mathrm{rpm}$, whereas the lowest absorption index was obtained at a barrel temperature of $100^{\circ} \mathrm{C}$ and a screw speed of $148 \mathrm{rpm}$. The 3 -dimensional surface plot shows that the water absorption index was at the highest when the barrel temperature and screw speed were at $120^{\circ} \mathrm{C}$ and $177 \mathrm{rpm}$, respectively. The water absorption index was shown to decrease when the screw speed increased to more than $177 \mathrm{rpm}$. Similar findings were reported by Pardhi et al. (2019), in which the authors noted that higher screw speeds resulted in a shorter time frame for the starch to remain in the barrel and thus, led to lower rates of water absorption for starch -based products. The increase in the rate of water absorption index was also shown to be proportionate to the barrel temperature due to the increase in starch degradation and starch shortening (Pelembe et al., 2002; Pardhi et al., 2019). Additionally, the water absorption index was also reduced when the duration of the extrusion process overlapped with the gelatinisation process (Altan et al., 2009; Pardhi et al., 2019). However, the water absorption index is dependent on the existence of intact starch molecules that do not lose their ability to bind water molecules after the extrusion process (Salata et al., 2014).

\subsection{Water solubility index}

The water solubility index is generally used as an indicator of the degradation of molecular components that are dependent on the state and type of reaction involved in the extrusion process. The water solubility index of the Amplang products ranged between 19.25 to 29.80 (Table 3). Based on the regression analysis, the barrel temperature coefficient was found to be highly significant $(P \leq 0.01)$, while the screw speed coefficient was not significant $(P>0.05)$. The corresponding interaction effects of the barrel temperature and screw speed were not found to be significant $(P>0.05)$. A high coefficient of determination $\left(\mathrm{R}^{2}\right)$ value of 0.8371 was obtained, thereby indicating that $83.71 \%$ of the 
variability in the water solubility index could be explained by the model and hence, represented the true relationships among the selected process parameters (Table 4).

Similarly, the water solubility response was shown to fit the quadratic model with a high coefficient determination $\left(\mathrm{R}^{2}\right)$ of 0.8731 and thus, represented the true relationships among the selected parameters. The water solubility index ranged between 19.25 to 29.80 at barrel temperatures of 100,120 , and $140^{\circ} \mathrm{C}$ and screw speeds of 146, 177, and $208 \mathrm{rpm}$, respectively. Additionally, the barrel temperature coefficient was shown to be significant $(P \leq 0.01)$, while the coefficient of the screw speed was not found to be significant $(\mathrm{P}>$ $0.05)$.

Based on Figure 1 (e), the highest water solubility index was achieved at a barrel temperature and screw speed of $140^{\circ} \mathrm{C}$ and $208 \mathrm{rpm}$, respectively. The water solubility index remained low although the barrel temperature increased. Similar to the water absorption index, the water solubility index increases proportionally with the increase in screw speed. In addition, the starch gelatinization process and other reactions that produce low molecular-weight compounds cause the release of amylose and amylopectin. Nevertheless, the increase in screw speed is thought to increase the shear rate and subsequently, increase water solubility. For instance, although higher screw speeds shorten the dwell time of the starch in the extruder, the amount of starch or fibres that have undergone the degradation processes is sufficient to increase water solubility (Arun Kumar et al., 2015). The authors also stated that water absorption and water solubility indexes are important parameters used to evaluate how the materials interact, particularly in applications that require the use of extrusion processes.

Apart from the screw speed, screw configuration and feed composition can also affect the extruder-induced water solubility index. Additionally, the increase in shear energy and dwell time in the barrel leads to degradation and polymerization of the starch molecular structure. It was previously noted that the high shear strength may cause the breakdown of starch and proteins, thus leading to degraded products with smaller and more soluble molecules (Arun Kumar et al., 2015; Pardhi et al., 2019).

Significant changes in the physical and functional properties were observed, in which bulk density, expansion ratio, water absorption index, and water solubility index of the extruded fish snacks were all shown to be significantly affected by the variation in barrel temperatures and screw speeds. In this study, Amplang was successfully developed using extrusion technology that has the potential to be applied in the production of local Amplang in Borneo. Specifically, a barrel temperature of $120^{\circ} \mathrm{C}$ and screw speed at $146 \mathrm{rpm}$ produced Amplang fish crackers that had a higher expansion rate and low bulk density, although it was slightly harder as compared to the commercially produced Amplang. More studies should be performed to improve the formulation and moisture content of the fish extrude to reduce its hardness. It is envisaged that this pilot study has the potential to be further improvised and used for the commercial production of Amplang in Borneo particularly in Sabah.

\section{Conflict of interest}

The authors declare no conflict of interest.

\section{Acknowledgments}

This study entitled 'The effects of extrusion conditions on the properties of Amplang, a traditional fish snack in Borneo' was financially supported by the University Malaysia Sabah internal grant (SBK0277STWN-2016). The authors are also grateful to the Food Technology Research Centre, MARDI, Serdang for the use of laboratory facilities and technical assistance provided.

\section{References}

Altan, A., Mccarthy, K. and Maskan, M. (2009). Effect of extrusion cooking on functional properties and in vitro starch digestibility of barley-based extrudates from fruit and vegetables by products. Journal of Food Science, 74(2), 77-86. https://doi.org/10.1111/ j.1750-3841.2009.01051.x

Anderson, R., Conway, H. and Peplinski, A. (1970). Gelatinization of corn grits by roll cooking, extrusion cooking and steaming. Starch/Starke, 22 (4), 130-135. https://doi.org/10.1002/ star. 19700220408

AOAC. (2000). Official methods of analysis of AOAC International. $15^{\text {th }}$ ed. Washington, D.C., USA: Association of Official Analytical Chemists.

Arun Kumar, T.V., Samuel, D.V.K., Jha, S.K. and Sinha, J.P. (2015). Twin screw extrusion of sorghum and soya blends: a response surface analysis. Journal of Agricultural Science and Technology, 17, 649-662.

Chng, N.M. and Kuang, H.K. (1991). Southeast Asian fish products. $2^{\text {nd }}$ ed. Singapore: Southeast Asian Fisheries Development Center.

Deshpande, H.W. and Poshadri, A. (2011). Physical and sensory characteristics of extruded snacks prepared from Foxtail millet based composite flours. International Food Research Journal, 18, 751-756. 
Dileep, A.O., Shamasundar, B.A., Binsi, P.K. and Howell, N.K. (2010). Composition and quality of rice flour-fish mince based extruded products with emphasis on thermal properties of rice flour. Journal of Texture Studies, 41(2), 190-207. https:// doi.org/10.1111/j.1745-4603.2010.00221.x

Hashimoto, J.M. and Grossmann, M.V. (2003). Effects of extrusion conditions on quality of cassava bran/ cassava starch extrudates. International Journal of Food Science and Technology, 38(5), 511-517. https://doi.org/10.1046/j.1365-2621.2003.00700.x

Ilo, S., Tomschik, U., Berghofer, E. and Mundigler, N. (2004). The effect of extrusion operating conditions on the apparent viscosity and the properties of extrudates in twin screw extrusion cooking of maize grits. Lebensmittel-Wissenschaft und-Technologie, 29(7), 593-598. https://doi.org/10.1006/ fstl.1996.0092

Maskus, H. and Arntfield, S. (2015). Extrusion processing and evaluation of an expanded, puffed peas snack product. Journal of Nutrition and Food Science, 5(4), 1000378.

Moscicki, L. (2011). Extrusion-cooking Techniques. Germany: Wiley-VCH Verlag and Co. https:// doi.org/10.1002/9783527634088

Myers, R.H. and Montgomery, D.C. (2002). Response surface methodology: process and products optimization using designed experiments. New York: Wiley.

Noorakmar, A.W., Cheow, C.S., Norizzah, A.R., Mohd Zahid, A. and Ruzaina, I. (2012). Effect of orange sweet potato (Ipomoea batatas) flour on the physical properties of fried extruded fish crackers. International Food Research Journal, 19(2), 657664.

Pardhi, S.D., Singh, B., Nayik, G.A. and Dar, B.N. (2019). Evaluation of functional properties of extruded snacks develop from brown rice grits by using response surface methodology. Journal of the Saudi Society of Agricultural Sciences, 18(1), 7-16. https://doi.org/10.1016/j.jssas.2016.11.006

Pelembe, L., Erasmus, C. and Taylor, J. (2002). Development of a protein-rich composite sorghum cowpea instant porridge by extrusion cooking process. LWT-Food Science and Technology, 35(2), 120-127. https://doi.org/10.1006/fst1.2001.0812

Raleng, A., Singh, A., Singh, B. and Attkan, A.K. (2016). Response surface methodology for development and characterization of extruded snack developed from food-by-products. International Journal of Bio-resource and Stress Management, 7 (6), 1321-1329. https://doi.org/10.23910/
IJBSM/2016.7.6.1691a

Rayas-Duarte, P., Majewska, K. and Doetkott, C. (1998). Effect of extrusion process parameters on the quality of buckwheat flourmixes. Cereal Chemistry, 75(3), 338-345. https://doi.org/10.1094/

CCHEM.1998.75.3.338

Salata, C.D., Leonel, M., Trombini, F.R. and Mischan, M.M. (2014). Extrusion of blends of cassava leaves and cassava flour: physical characteristics of extrudates. Food Science and Technology, 34, 501506. https://doi.org/10.1590/1678-457x.6337

Shankar, T. and Bandyopadhyay, S. (2005). Process variables during single screw extrusion of fish and rice-flour blends. Food Processing and Preservation, 29(2), 151-164. https://doi.org/10.1111/j.17454549.2005.00020.x

Singh, R.K.R., Majumdar, R.K. and Venkateshwarlu, G. (2014). Optimum extrusion-cooking conditions for improving physical properties of fish-cereal based snacks by response surface methodology. Journal of Food Science and Technology, 51, 1827-1836. https://doi.org/10.1007/s13197-012-0725-9

Taewee, T. K. (2011). Cracker "Keropok": A review on factors influencing expansion. International Food Research Journal, 18(3), 855-866.

Thymi, S., Krokida, K., Pappa, Z. and Maroulis, B. (2005). Structural properties of extruded corn starch. Journal of Food Engineering, 68(4), 519-526. https://doi.org/10.1016/j.jfoodeng.2004.07.002

Tumuluru, J.S. and Sokhansanj, S. (2013). Changes in moisture, protein and fat content of fish and rice flour coextrudates during single-screw extrusion cooking. Food and Bioprocess Technology, 6(8), 403-415. https://doi.org/10.1007/s11947-011-0764-7

Verma, D.K. (2010). Optimization of process parameters for development of protein enriched rice (Oryza sativa) based snack food through extrusion cooking. Jabalpur: JNKVV.

Wani, S., Solanke, N. and Kumar, P. (2015). Extruded product based on oat and fenugreek and their storage stability. Current Nutrition and Food Science, 11(1), 78-84. https:// doi.org/10.2174/1573401311666150304235616 